\title{
The Impact on Blood Pressure of a Short-Term Change in Indoor Temperature
}

\author{
Xi Chen ${ }^{1, *}$ \\ Ping $\mathrm{Tu}^{2, *}$ \\ Xing-Lan Sun $\mathbb{D}^{\prime}$ \\ Ting-Ying $\mathrm{Hu}^{\prime}$ \\ Jia Wan' \\ Yi-Wei Hu' \\ Hui-Ling Zhou' \\ Hai Su' \\ 'Department of Cardiovascular Medicine, \\ The Second Affiliated Hospital of \\ Nanchang University, Nanchang, 330006, \\ People's Republic of China; ${ }^{2}$ Department \\ of Post Anesthesia Care Unit, The \\ Second Affiliated Hospital of Nanchang \\ University, Nanchang, 330006, People's \\ Republic of China \\ *These authors contributed equally to \\ this work
}

Correspondence: Xing-Lan Sun Department of Cardiovascular Medicine, The Second Affiliated Hospital of Nanchang University, No. I of Minde Road, Donghu District, Nanchang, 330006, People's Republic of China Tel $+86791-86312182$

Fax +86 791-86312182

Email sunxinglan_99dr@163.com
Objective: The aim of this study is to evaluate the impact on blood pressure (BP) of a $10^{\circ} \mathrm{C}$ change in room temperature (between $18^{\circ} \mathrm{C}$ and $28^{\circ} \mathrm{C}$ ).

Methods: A total of 112 volunteers, 56 males and 56 females, 55 with and 57 without hypertension, were enrolled in the study. First, the participants were placed in a $25^{\circ} \mathrm{C}$ room. Second, they were randomly assigned to either a $28^{\circ} \mathrm{C}$ (group A) or an $18^{\circ} \mathrm{C}$ room (group B). Finally, they were moved from the $28^{\circ} \mathrm{C}$ to the $18^{\circ} \mathrm{C}$ room, or vice versa. They stayed in each room for 20 minutes. Seated BP was measured at the 17th and 19th minute in each room, and the average was used. The difference in the subject's BP between the second two rooms was recorded as delta BP.

Results: The baseline systolic BP (SBP), age, gender distribution, and incidence of hypertension were similar between the two groups. In group $\mathrm{A}$, the decrease in room temperature of $10^{\circ} \mathrm{C}$ induced a mean rise in SBP of $4.1 \mathrm{mmHg}$. In group $\mathrm{B}$, the increase of $10^{\circ} \mathrm{C}$ caused SBP to decrease by $4.0 \mathrm{mmHg}$. When compared with the group without hypertension, the group with hypertension had a significantly higher rise in mean SBP (6.8 vs $1.2 \mathrm{mmHg}$ ) as a result of the decrease in temperature and a significantly higher drop in SBP (7.3 vs 1.2 $\mathrm{mmHg}$ ) as a result of the increase in temperature. The participants in the group with hypertension were older.

Conclusion: A $10^{\circ} \mathrm{C}$ change in room temperature, from $18^{\circ} \mathrm{C}$ to $28^{\circ} \mathrm{C}$, for $20 \mathrm{~min}$ can cause a significant change in SBP. The extent of this change is more obvious in the older group.

Keywords: room, temperature, BP, hypertension, change

\section{Introduction}

Blood pressure (BP) is generally higher in cold seasons than in warm seasons. Increased mortality from cardiovascular disease in winter is partly explained by the increased BP induced by exposure to the cold.

Generally, changes in outdoor temperatures have been considered as the reason for seasonal BP changes. ${ }^{1-4}$ A study showed that outdoor temperature was inversely associated with BP in 438,811 Chinese adults. ${ }^{2}$ In addition, a meta-analysis indicated that a $1^{\circ} \mathrm{C}$ decrease in mean daily outdoor temperature was associated with an increase in systolic BP (SBP) of $0.26 \mathrm{mmHg}$ and diastolic BP (DBP) of 0.13 mmHg. ${ }^{4}$ Otsuki et al found that SBP during outdoor exercise was associated with the air temperature. ${ }^{5}$

Recently, the impact of indoor temperature on BP has attracted more attention. $^{4,6,7}$ A study suggested that a change in indoor temperature has a more obvious impact on BP than a change in outdoor temperature. For example, the above-mentioned meta-analysis indicated that a $1^{\circ} \mathrm{C}$ decrease was associated with 
an increase of $0.38 \mathrm{mmHg}$ in $\mathrm{SBP}^{4}$ However, based on the data from 4659 community-dwelling adults, Zhao et al found that a $1^{\circ} \mathrm{C}$ decrease in indoor temperature was associated with a $0.48 \mathrm{mmHg}$ increase in SBP and a 0.45 $\mathrm{mmHg}$ increase in DBP, after controlling for confounding variables. $^{7}$

Some scholars consider that the relationship between $\mathrm{BP}$ and indoor temperature is not completely linear. When the indoor temperature is below $18^{\circ} \mathrm{C}$, a decrease in indoor temperature may induce a more obvious increase in BP when compared with changes above $18^{\circ} \mathrm{C}$. Therefore, an indoor temperature above $18^{\circ} \mathrm{C}$ is recommended for the prevention of high BP in humans. ${ }^{8}$

A change in room temperature in the range of $18^{\circ} \mathrm{C}-$ $28^{\circ} \mathrm{C}$ is common at home or in hospital. Currently, the impact of this change on BP is unclear. If it were discovered that this change in room temperature could cause variation in BP, this information would be useful for the diagnosis of and research into hypertension. This study mainly evaluated the impact of a $10^{\circ} \mathrm{C}$ change in room temperature for 20 minutes on the BP of a group of volunteers.

\section{Methods}

\section{Subjects}

A total of 112 volunteers, 56 males and 56 females, were enrolled in this study (age: $18-80$ years old). According to their disease history, 55 had hypertension and 57 did not. The study was conducted in accordance with the Declaration of Helsinki (as revised in 2013). The study was approved by the Ethics Committee of the Second Affiliated Hospital of Nanchang University, and all participants gave informed consent. Hypertensives patients took Annezen (Amlozepin Benzylate Tablets $5 \mathrm{mg}-$ 10 mg/day), Annexide (Losartan Potassium 50 mg/ Hydrochlorothiazide Tablets $12.5 \mathrm{mg}, 1$ tablet/day).

\section{Study Design}

The participants were asked to abstain from caffeine and alcohol and to avoid intense physical activity. In this study, three rooms were maintained using central air conditioning at $25^{\circ} \mathrm{C}, 28^{\circ} \mathrm{C}$, and $18^{\circ} \mathrm{C}$, respectively. Room humidity was $50-60 \%$. The experiment was carried out in winter and spring from 08:00 to $12: 00$ and 14:00 to $17: 30$.

First, all the participants were placed in the $25^{\circ} \mathrm{C}$ room. Second, they were randomly assigned to the $28^{\circ} \mathrm{C}$ (group A) or the $18^{\circ} \mathrm{C}$ (group B) room. Finally, the participants in group A moved to the $18^{\circ} \mathrm{C}$ room, ie, from $25^{\circ} \mathrm{C}$ to $28^{\circ} \mathrm{C}$ to $18^{\circ} \mathrm{C}$, and those in group $\mathrm{B}$ moved to the $28^{\circ} \mathrm{C}$ room, ie, from $25^{\circ} \mathrm{C}$ to $18^{\circ} \mathrm{C}$ to $28^{\circ} \mathrm{C}$. This means that in the last stage, group A experienced a decrease in room temperature of $10^{\circ} \mathrm{C}$, while group $\mathrm{B}$ experienced an increase of $10^{\circ} \mathrm{C}$. The participants stayed in each room for 20 minutes, and they could put on or remove items of clothing according to how they were feeling (Figure 1).

\section{BP Measurement}

Blood pressure testers: research nurses;

Participants: The blood pressure was measured in a sitting position to protect and relax. The thickness of the jacket was no more than $0.5 \mathrm{~cm}$. The lower edge of the cuff was $2 \sim 3 \mathrm{~cm}$ above the elbow socket, and it was considered to be moderately tight if two fingers could fit into it.

Cuff: the cuff for ordinary people to use the electronic blood pressure monitor is $22-32 \mathrm{~cm}$, and the cuff for obese people to use the electronic blood pressure monitor is $32-45 \mathrm{~cm}$.

First, a cuff was carefully placed on the right arm of the participant. In this study, seated BP was measured using an electronic (oscillometric) BP device (Omron HEM-7201) in each room at the 17th and 19th minute. The average of these two measurements was recorded as the final value for each participant. The BP was measured with the same BP device for each participant.

The BP measured in the $25^{\circ} \mathrm{C}$ room was recorded as the baseline BP (BP-25). The BPs measured in the $28^{\circ} \mathrm{C}$ and $18^{\circ} \mathrm{C}$ rooms were recorded as $\mathrm{BP}-28$ and $\mathrm{BP}-18$, respectively. The difference in $\mathrm{BP}$ between the $28^{\circ} \mathrm{C}$ and $18^{\circ} \mathrm{C}$ rooms was recorded as delta $\mathrm{BP}$, and the difference in temperature was recorded as delta $\mathrm{T}$. The $\mathrm{BP}$ change rate was calculated using the following formula: Delta BP $\div$ Delta $\mathrm{T}\left(\mathrm{mmHg} /{ }^{\circ} \mathrm{C}\right)$.

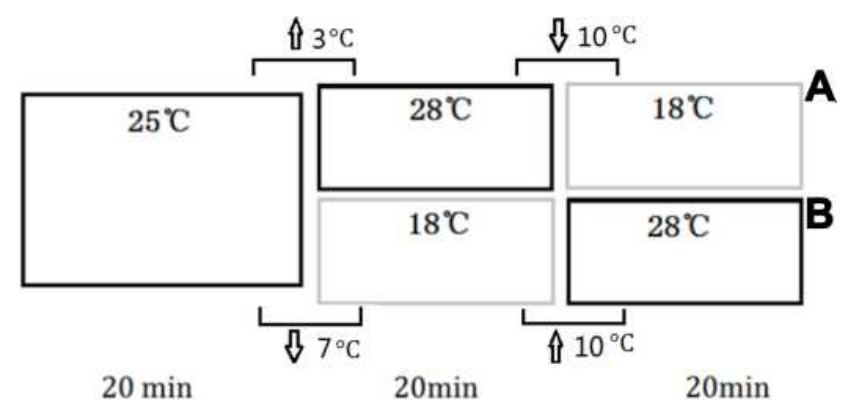

Figure I The scheme of the study proposal. 


\section{Statistical Analysis}

All data were presented as mean \pm standard deviation, and the SPSS 21.0 statistical package was used for the analysis. A $t$-test was performed for the comparison of continuous variables, and a paired $t$-test was performed for the comparison of paired data. Categorical variables presented as a percentage were analyzed using the Pearson Chi-square test. $\mathrm{P}<0.05$ was considered statistically significant.

\section{Results}

The baseline BP, age, distribution of gender, and incidence of hypertension were similar between the two groups (Table 1).

When the participants in group A moved from the $28^{\circ} \mathrm{C}$ to the $18^{\circ} \mathrm{C}$ room $\left(10^{\circ} \mathrm{C}\right.$ decrease $)$, their mean SBP increased by $4.1 \mathrm{mmHg}$, a rate of increase of $0.41 \mathrm{mmHg} /{ }^{\circ} \mathrm{C}$, and their mean DBP increased by $3.6 \mathrm{mmHg}$, a rate of increase of $0.36 \mathrm{mmHg} /{ }^{\circ} \mathrm{C}$. When the participants in group $\mathrm{B}$ moved from the $25^{\circ} \mathrm{C}$ to the $18^{\circ} \mathrm{C}$ room $\left(7^{\circ} \mathrm{C}\right.$ decrease), their mean SBP increased by $2.7 \mathrm{mmHg}$, a rate of increase of 0.39 $\mathrm{mmHg} /{ }^{\circ} \mathrm{C}$, and their mean DBP increased by $3 \mathrm{mmHg}$, a rate of increase of $0.43 \mathrm{mmHg} /{ }^{\circ} \mathrm{C}$.

When the participants in group $\mathrm{B}$ moved from the $18^{\circ} \mathrm{C}$ to the $28^{\circ} \mathrm{C}$ room, their mean SBP decreased by 4.0 $\mathrm{mmHg}$, a rate of decline of $0.40 \mathrm{mmHg} /{ }^{\circ} \mathrm{C}$, and their mean DBP decreased by $1.3 \mathrm{mmHg}$, a rate of decline of $0.13 \mathrm{mmHg} /{ }^{\circ} \mathrm{C}$. When group A moved from the $25^{\circ} \mathrm{C}$ to the $28^{\circ} \mathrm{C}$ room $\left(3^{\circ} \mathrm{C}\right.$ increase), their mean SBP decreased by $0.8 \mathrm{mmHg}$, a rate of decline of $0.26 \mathrm{mmHg} /{ }^{\circ} \mathrm{C}$, and their mean DBP decreased by $0.6 \mathrm{mmHg}$, a rate of decline of $0.20 \mathrm{~mm} \mathrm{Hg} /{ }^{\circ} \mathrm{C}$ (no statistical significance) (Table 2).

The participants in the group with hypertension, who were significantly older, had higher BP-25 levels than

Table I The Age and Gender of the A and B Groups

\begin{tabular}{|l|l|l|l|l|}
\hline & & $\mathbf{N}(\%)$ & Age (y) & BMI $\left(\mathbf{k g} / \mathbf{m}^{2}\right)$ \\
\hline A & Total & 56 & $41.0 \pm 19.3$ & $22.46 \pm 3.93$ \\
& Male & $28(50 \%)$ & $42.2 \pm 20.2$ & \\
& Female & $28(50 \%)$ & $39.8 \pm 18.8$ & \\
& HT & $29(51.8 \%)$ & $57.7 \pm 3.0$ & \\
& Non-HT & $27(48.2 \%)$ & $23.0 \pm 18.8$ & \\
\hline B & Total & 56 & $39.1 \pm 19.9$ & $23.58 \pm 4.56$ \\
& Male & $28(50 \%)$ & $37.5 \pm 18.8$ & \\
& Female & $28(50 \%)$ & $40.8 \pm 21.1$ & \\
& HT & $26(46.4 \%)$ & $57.7 \pm 14.2$ & \\
& Non-HT & $30(54.6 \%)$ & $23.1 \pm 1.6$ & \\
& & & & $\mathrm{P}=0.166$ \\
\hline
\end{tabular}

Abbreviation: HT, hypertension. those in the group without hypertension, but the gender distribution was similar between the two groups (Table 3 ).

Figure 2 compares the change in SBP and DBP between the group with and the group without hypertension when the room temperature changed by $10^{\circ} \mathrm{C}$. The group with hypertension had a significantly higher increase in mean SBP (6.8 $\mathrm{mmHg}$ vs $1.2 \mathrm{mmHg}, \mathrm{p}=0.014$ ) when the room temperature decreased by $10^{\circ} \mathrm{C}$ and a significantly higher decrease in SBP (7.3 mmHg vs $1.2 \mathrm{mmHg}, \mathrm{p}=0.021$ ) when the room temperature increased by $10^{\circ} \mathrm{C}$. However, for DBP the values were $4.8 \mathrm{mmHg}$ vs $2.4 \mathrm{mmHg}(\mathrm{p}=0.206)$ and $2.7 \mathrm{mmHg}$ vs $0.03 \mathrm{mmHg}(\mathrm{p}=0.208)$, respectively, but there is no statistical significance (Figure 2).

\section{Discussion}

A previous study found that when the room temperature was above $18^{\circ} \mathrm{C}$, the temperature change had a relatively weak impact on $\mathrm{BP} .{ }^{8}$ Therefore, this study set the lowest room temperature at $18^{\circ} \mathrm{C}$.

Our results demonstrated that an increase or decrease in temperature of $10^{\circ} \mathrm{C}$, between $18^{\circ} \mathrm{C}$ and $28^{\circ} \mathrm{C}$, may induce a significant decrease or increase in both SBP and DBP. When the room temperature decreased by $10{ }^{\circ} \mathrm{C}$, the rate of increase was $0.41 \mathrm{mmHg} /{ }^{\circ} \mathrm{C}$ for $\mathrm{SBP}$ and 0.36 $\mathrm{mmHg} /{ }^{\circ} \mathrm{C}$ for DBP. Interestingly, a decrease in room temperature of $7^{\circ} \mathrm{C}$ induced a similar rate of increase of 0.39 $\mathrm{mmHg} /{ }^{\circ} \mathrm{C}$ for $\mathrm{SBP}$ and $0.43 \mathrm{mmHg} /{ }^{\circ} \mathrm{C}$ for DBP. Previously, a study ${ }^{4}$ indicated that a $1{ }^{\circ} \mathrm{C}$ decrease in indoor temperature was associated with a $0.38 \mathrm{mmHg}$ increase in SBP. In addition, Zhao et al found that a $1{ }^{\circ} \mathrm{C}$ decrease in indoor temperature was associated with a rise of $0.48 \mathrm{mmHg}$ in SBP and $0.45 \mathrm{mmHg}$ in DBP. ${ }^{7}$ These values indicate that a $1{ }^{\circ} \mathrm{C}$ decrease in indoor temperature is associated with an increase of $0.4-0.5 \mathrm{mmHg}$ in SBP and of $0.35-0.45 \mathrm{mmHg}$ in DBP.

Our results demonstrated that an increase in room temperature of $10^{\circ} \mathrm{C}$ could decrease SBP, with a rate of 0.40 $\mathrm{mmHg} /{ }^{\circ} \mathrm{C}$, and that the absolute value of this decrease is very close to that of the rate of increase induced by a $10^{\circ} \mathrm{C}$ decrease in room temperature. However, this change in room temperature did not induce a significant decrease in DBP (a rate of decline of only $0.13 \mathrm{mmHg} /{ }^{\circ} \mathrm{C}$ ). These results indicated that the DBP response to the change in temperature may be different to the SBP response. Although the exact mechanism is unclear, a possible reason is that cold exposure could rapidly increase the sympathetic activity, while warm exposure could not rapidly decrease the sympathetic activity. ${ }^{2,9-14}$ 
Table 2 The BP Change Between the A and B Groups in the Rooms with Different Temperatures

\begin{tabular}{|l|c|c|c|c|}
\hline \multirow{2}{*}{ Items } & \multicolumn{2}{|c|}{ A (2) } & \multicolumn{2}{c|}{ B (I) } \\
\cline { 2 - 5 } & SBP $(\mathbf{m m H g})$ & DBP $(\mathbf{m m H g})$ & SBP (mmHg) & DBP (mmHg) \\
\hline First room $\left(25^{\circ} \mathrm{C}\right)$ & $121.4 \pm 19.0$ & $76.9 \pm 12.6$ & $121.8 \pm 20.2$ & $74.9 \pm 14.1$ \\
\hline Second room $\left(28^{\circ} \mathrm{C}\right)$ & $120.6 \pm 18.52$ & $76.3 \pm 11.6$ & $124.5 \pm 23.4$ & $77.9 \pm 15.9$ \\
\hline Third room $\left(18^{\circ} \mathrm{C}\right)$ & $124.7 \pm 22.3$ & $79.9 \pm 14.4$ & $120.5 \pm 20.1$ & $76.6 \pm 13.6$ \\
\hline TI-2 & 0.760 & $\begin{array}{c}0.236 \\
(-1.276,2.834)\end{array}$ & $(-1.292,1.637)$ & -2.480 \\
\hline P & 0.450 & 0.814 & 0.037 & $(-5.263,-0.559)$ \\
\hline T2-3 & -3.528 & -3.574 & 3.128 & 0.016 \\
\hline P & $(-6.431,-1.772)$ & $(-5.551,-1.687)$ & $(1.444,6.592)$ & $(-0.874,3.37)$ \\
\hline
\end{tabular}

Notes: TI-2: $\mathrm{t}$ value compared between first room temperature and second room temperature. T2-3: $\mathrm{t}$ value compared between second room temperature and third room temperature.

Table 3 The Age and BP Levels of the Groups with and without Hypertension

\begin{tabular}{|l|l|l|l|l|l|}
\hline & N & Male (\%) & Age (y) & SBP (mmHg) & DBP (mmHg) \\
\hline HT & 55 & $29(52.73 \%)$ & $57.7 \pm 12.6$ & $133.1 \pm 20.3$ & $81.5 \pm 15.4$ \\
Non-HT & 57 & $27(47.37 \%)$ & $23.1 \pm 2.4$ & $110.5 \pm 10.2$ & $70.1 \pm 7.63$ \\
P & 1 & NS & $<0.001$ & $<0.001$ & $<0.001$ \\
\hline
\end{tabular}

Abbreviation: $\mathrm{HT}$, hypertension.

In addition, we found that an increase in room temperature of $3^{\circ} \mathrm{C}$ did not induce a significant decrease in SBP or DBP. However, a previous study found that a rise in room temperature of $2.09^{\circ} \mathrm{C}$ could significantly decrease SBP and DBP by $4.43 \mathrm{mmHg}$ and $2.33 \mathrm{mmHg}$, respectively. ${ }^{6}$ This difference may be due to the short

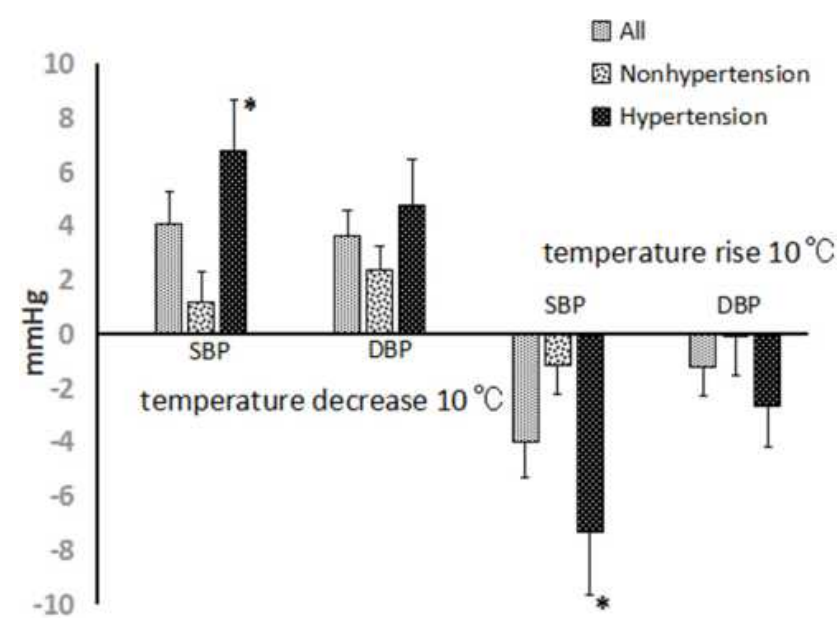

Figure 2 The change in SBP and DBP induced by room temperature change between the groups with and without hypertension (mean $\pm \mathrm{SD}$ ). *Compared with the group without hypertension, $p<0.05 .56$ participants in each group. length of time $(20 \mathrm{~min})$ that the participants spent in each room in our study.

Our study also found that the group with hypertension, who were older, had a larger change in BP when the room temperature changed by $10^{\circ} \mathrm{C}$ than the younger group without hypertension. As both the age and the baseline BP levels in the group with hypertension were higher, these two factors may also be related to the excessive change in $\mathrm{BP}^{15,16}$ Based on our results, more attention should be paid to older patients and patients with hypertension when the room temperature changes, especially when the room temperature decreases.

\section{Clinical Implications}

Our study showed that even though the participants could freely put on or remove items of clothing, a $10^{\circ} \mathrm{C}$ change in room temperature for only $20 \mathrm{~min}$ can induce a change in SBP of about $4 \mathrm{mmHg}$. However, this change was about $7 \mathrm{mmHg}$ in the older group with hypertension. Therefore, this finding should be considered in clinical diagnosis and management of hypertension and in hypertension research, especially for the elderly and those with hypertension. 


\section{Limitations}

Potential limitations may have affected this study. First, this study involved only a small population. Therefore, the findings must be treated with caution. Second, the participants with hypertension in this study were older than those without hypertension. Therefore, we could not fully explain the impact of hypertension on the change in BP induced by changes in room temperature. Third, the impact of anti-hypertensive treatment on the relationship between $\mathrm{BP}$ and room temperature was not analyzed in depth, since the sample was small. Also, The sample is restricted and of young age. The main limitation is the selection of participants (no report), the restricted sample size, and the fact that we did not use a cross-over design for all participants which would increase study power.

\section{Conclusions}

A change in room temperature of $10^{\circ} \mathrm{C}$, between $18^{\circ} \mathrm{C}$ and $28^{\circ} \mathrm{C}$, for $20 \mathrm{~min}$ induced a mean change of $4 \mathrm{mmHg}$ in the SBP of 112 volunteers. However, the change was about $7 \mathrm{mmHg}$ in the older group with hypertension.

\section{Acknowledgments}

We are particularly grateful to all the people who have given us help on our article.

\section{Funding}

There is no funding to report.

\section{Disclosure}

The authors declare that they have no competing interests.

\section{References}

1. Giaconi S, Ghione S, Palombo C, et al. Seasonal influences on blood pressure in high normal to mild hypertensive range. Hypertension. 1989;14(1):22-27. doi:10.1161/01.hyp.14.1.22

2. Wang S, Li M, Hua Z, et al. Outdoor temperature and temperature maintenance associated with blood pressure in 438,811 Chinese adults. Blood Press. 2017;26(4):246-254. doi:10.1080/08037051.2017.1297676

3. Yatabe J, Yatabe MS, Morimoto S, Watanabe T, Ichihara A. Effects of room temperature on home blood pressure variations: findings from a long-term observational study in Aizumisato Town. Hypertens Res. 2017;40(8):785-787. doi:10.1038/hr.2017.18

International Journal of General Medicine

\section{Publish your work in this journal}

The International Journal of General Medicine is an international, peer-reviewed open-access journal that focuses on general and internal medicine, pathogenesis, epidemiology, diagnosis, monitoring and treatment protocols. The journal is characterized by the rapid reporting of reviews, original research and clinical studies
4. Wang Q, Li C, Guo Y, et al. Environmental ambient temperature and blood pressure in adults: a systematic review and meta-analysis. Sci Total Environ. 2017;575:276-286. doi:10.1016/j.scitotenv.2016.10.019

5. Otsuki T, Ishii N. Association between blood pressure changes during self-paced outdoor walking and air temperature. Clin Physiol Funct Imaging. 2017;37(2):155-161. doi:10.1111/cpf.12280

6. Saeki K, Obayashi K, Kurumatani N. Short-term effects of instruction in home heating on indoor temperature and blood pressure in elderly people: a randomized controlled trial. J Hypertens. 2015;33 (11):2338-2343. doi:10.1097/HJH.0000000000000729

7. Zhao H, Jivraj S, Moody A. 'My blood pressure is low today, do you have the heating on?' The association between indoor temperature and blood pressure. J Hypertens. 2019;37(3):504-512. doi:10.1097/ HJH.0000000000001924

8. Shiue I, Shiue M. Indoor temperature below $18^{\circ} \mathrm{C}$ accounts for $9 \%$ population attributable risk for high blood pressure in Scotland. Int J Cardiol. 2014;171(1):e1-e2. doi:10.1016/j.ijcard.2013.11.040

9. Xu D, Zhang Y, Wang B, et al. Acute effects of temperature exposure on blood pressure: an hourly level panel study. Environ Int. 2019;124:493-500. doi:10.1016/j.envint.2019.01.045

10. Brook RD, Weder AB, Rajagopalan S. "Environmental hypertensionology" the effects of environmental factors on blood pressure in clinical practice and research. J Clin Hypertens (Greenwich). 2011;13 (11):836-842. doi:10.1111/j.1751-7176.2011.00543.x

11. Cui J, Muller MD, Blaha C, Kunselman AR, Sinoway LI. Seasonal variation in muscle sympathetic nerve activity. Physiol Rep. 2015;3 (8):e12492. doi:10.14814/phy2.12492

12. Ushigome E, Kitagawa N, Kitae A, et al. Seasonal variation in home blood pressure and its relationship with room temperature in patients with type 2 diabetes. Diab Vasc Dis Res. 2020;17(1):1479164119883986. doi:10.1177/ 1479164119883986

13. Huang CC, Chen YH, Hung CS, et al. Assessment of the relationship between ambient temperature and home blood pressure in patients from a web-based synchronous telehealth care program: retrospective Study. J Med Internet Res. 2019;21(3):e12369. doi:10.2196/12369

14. Umishio W, Ikaga T, Kario K, et al.; SWH Survey Group. Crosssectional analysis of the relationship between home blood pressure and indoor temperature in winter: a nationwide smart wellness housing survey in Japan. Hypertension. 2019;74(4):756-766. doi:10.1161/ HYPERTENSIONAHA.119.12914

15. Stergiou GS, Palatini P, Modesti PA, et al. Seasonal variation in blood pressure: evidence, consensus and recommendations for clinical practice. Consensus statement by the European society of hypertension working group on blood pressure monitoring and cardiovascular variability. $J$ Hypertens. 2020;38(7):1235-1243. doi:10.1097/HJH.0000000000002341

16. Kollias A, Kyriakoulis KG, Stambolliu E, Ntineri A, Anagnostopoulos I, Stergiou GS. Seasonal blood pressure variation assessed by different measurement methods: systematic review and meta-analysis. $J$ Hypertens. 2020;38(5):791-798. doi:10.1097/ HJH.0000000000002355

across all disease areas. The manuscript management system is completely online and includes a very quick and fair peer-review system, which is all easy to use. Visit http://www.dovepress.com/ testimonials.php to read real quotes from published authors. 